\title{
Stereotactic body radiotherapy for the treatment of medically inoperable primary renal cell carcinoma: Current evidence and future directions
}

\author{
Anand Swaminath, MD, FRCPC, ${ }^{* \psi_{5}}$ William Chu, $M D^{ \pm}$
}

*Department of Oncology, McMaster University, Hamilton, ON; ${ }^{ \pm D}$ epartment of Radiation Oncology, Odette Cancer Centre, Sunnybrook Health Sciences Centre, University of Toronto, ON; § §uravinski Cancer Centre, Hamilton, $0 \mathrm{~N}$

Cite as: Can Urol Assoc J 2015;9(7-8):275-80. http://dx.doi.org/10.5489/cuaj.2900

Published online August 10, 2015.

\begin{abstract}
The incidence of renal cell carcinoma (RCC) is steadily rising due to an aging population and more frequent imaging of the abdomen for other medical conditions. While surgery remains the standard of care treatment for localized disease, many patients are unfit due to their advanced age and medical comorbidities. In these patients, an active surveillance strategy or ablative therapies, including radiofrequency/microwave ablation or cryotherapy, can be offered. Such options have limitations particularly with fast growing, or larger tumors. A promising ablative therapy option to consider is stereotactic body radiotherapy (SBRT). SBRT refers to high dose, focally ablative radiation delivered in a short time (3-5 fractions), and is safe and effective in many other cancer sites, including lung, liver and spine. SBRT offers potential advantages in the primary kidney cancer setting due to its ablative dosing (overcoming the notion of "radio-resistance"), short treatment duration (important in an elderly population), low toxicity profile (enabling SBRT to treat larger RCCs than other ablative modalities), and non-invasiveness. To date, there is limited long-term prospective data on the outcomes of SBRT in primary RCC. However, early evidence is intriguing with respect to excellent local control and low toxicity; however, most studies vary in terms of technique and radiation dosing used. Welldesigned prospective cohort studies with clearly defined and standardized techniques, dosing, follow-up, and integration of quality of life outcomes will be essential to further establish the role of SBRT in management of inoperable, localized RCC.
\end{abstract}

\section{Introduction}

In 2014, renal cell carcinoma (RCC) was the 6th and 11th most common cancer diagnosed in men and women, respectively in Canada. About 6000 new cases of RCC were diagnosed in 2014, with 1750 related deaths. ${ }^{1}$ The incidence of RCC has steadily risen by $1.3 \%$ from 2001 to $2010 .^{1}$
This is likely due to an aging population and an increase in abdominal computed tomography $(\mathrm{CT})$ in detecting asymptomatic renal masses. The standard of care for patients with localized RCC is surgical resection via total (T1b or higher) or partial (nephron-sparing) nephrectomy (for smaller tumors). ${ }^{2}$ Patients in general must be relatively healthy and fit to undergo surgery, but many are not offered surgery due to advanced age or medical comorbidities. In these patients, active surveillance is one management option; ${ }^{3}$ however it may not be desirable if there is evidence of fast growth kinetics, ${ }^{4}$ in association with male gender, symptomatic disease, younger age, and tumours $>2.5 \mathrm{~cm} .{ }^{5}$ For small T1a RCCs, ablative percutaneous techniques, such as cryotherapy, microwave ablation and radiofrequency ablation, are alternative strategies. ${ }^{6}$ However they are less effective with larger tumours (T1b or higher), and although minimally invasive, may be challenging to offer to select elderly and infirm patients.

The role of radiotherapy (RT) in RCC is limited. There is a belief that RCC is inherently "radio-resistant" when conventional RT (CRT) doses have been applied. A meta-analysis of randomized trials of adjuvant CRT showed no significant improvement in overall or disease-free survival, although these trials were not performed in a modern RT era. ${ }^{7}$ The main use of RT to date has been in the metastatic setting to palliate symptomatic bone and brain metastases, where short course RT doses have symptomatic benefit. ${ }^{8,9}$

Over the past 10 to 15 years, there have been tremendous advances in RT practice, permitting use of high precision RT planning and delivery techniques. These achievements have culminated in the ability to prescribe high dose, ablative RT to tumour targets anywhere in the body, while creating steep dose gradients that minimize damage to nearby critical organs. This treatment is referred to as stereotactic body radiotherapy (SBRT). We describe the application of SBRT in detail as it pertains to treatment of inoperable primary RCC. 


\section{SBRT defined}

The Canadian Association of Radiation Oncology defines SBRT as the precise delivery of highly conformal and image-guided hypofractionated external beam radiotherapy, delivered in a single or few fraction(s). ${ }^{10}$ Initially known as stereotactic radiosurgery (SRS), the technology was first conceptualized in 1949 as a non-invasive method to manage both benign and malignant intracranial lesions. ${ }^{11}$ This led to the development of the first SRS machine called the Gamma Knife, which uses radioactive Cobalt-60 sources in a fixed "helmet-like" frame to deliver small beams of radiation from many angles, summating onto intracranial targets with millimetric precision. ${ }^{12}$

SBRT is a natural progression from SRS. Instead of a fixed head frame, patients are now generally immobilized using a "frameless" stereotactic body system; and image-guided radiotherapy (IGRT) has been developed to ensure the tumour is being targeted precisely and accurately. ${ }^{13}$ It was not until the recent emergence of SBRT that high doses of RT could be safely and accurately delivered to small, moving extracranial targets. In comparison to CRT, which typically

\begin{tabular}{|c|c|c|}
\hline Characteristic & Conventional RT & SBRT \\
\hline Total radiation dose & $45-50 \mathrm{~Gy}$ & 30-45 Gy \\
\hline Dose per fraction & $1.8-2 \mathrm{~Gy}$ & 6-12 Gy \\
\hline No. fractions & $25-30$ & $3-5$ \\
\hline $\begin{array}{l}\text { Total treatment } \\
\text { duration }\end{array}$ & 5-6 weeks & $1-2$ weeks \\
\hline $\begin{array}{l}\text { Treatment time per } \\
\text { fraction }\end{array}$ & 5-10 minutes & 15-45 minutes \\
\hline $\begin{array}{l}\text { Maximum dose in } \\
\text { tumour }\end{array}$ & $\begin{array}{c}\text { 95-105\% of } \\
\text { prescription dose }\end{array}$ & $\begin{array}{c}100-140 \% \text { of } \\
\text { prescription dose }\end{array}$ \\
\hline $\begin{array}{l}\text { Image guidance } \\
\text { used }\end{array}$ & Occasionally & Routinely \\
\hline \multicolumn{3}{|l|}{ Indications } \\
\hline Primary RCC & Minimal & Emerging \\
\hline Adjuvant therapy & $\begin{array}{l}\text { Uncommon, no } \\
\text { survival benefit }\end{array}$ & Not studied \\
\hline $\begin{array}{l}\text { Neoadjuvant/pre- } \\
\text { surgical therapy }\end{array}$ & None & Possible \\
\hline Metastatic disease & Palliative & $\begin{array}{c}\text { Radical } \\
\text { (oligometastases) }\end{array}$ \\
\hline \multicolumn{3}{|l|}{ Limitations } \\
\hline Technical & $\begin{array}{l}\text { Inability to dose } \\
\text { escalate due to } \\
\text { bowel/kidney } \\
\text { tolerance }\end{array}$ & $\begin{array}{c}\text { Challenging when } \\
\text { in close proximity } \\
\text { to Gl structures }\end{array}$ \\
\hline Outcomes & $\begin{array}{l}\text { No survival benefit in } \\
\text { adjuvant setting }\end{array}$ & $\begin{array}{l}\text { Although good } \\
\text { local control in } \\
\text { primary setting, } \\
\text { need long term } \\
\text { follow-up }\end{array}$ \\
\hline
\end{tabular}

delivers small amounts of daily radiation (1.8-2 Gy/fraction) over a 5- to 7-week period, SBRT permits higher dose, ablative treatment, capable of permanent tumour control, in a very short time (typically 1-6 fractions, 5-20 Gy/fraction). From a radiobiological perspective, the SBRT-related mechanism of tumour damage is completely different compared to CRT. While CRT relies on oxygen dependent DNA damage, the effect of SBRT is likely more related to novel apoptotic pathways that result in endothelial cell damage. ${ }^{14}$ This is highly relevant in RCC, which relies on a rich vascular and angiogenic microenvironment (Table 1).

SBRT has revolutionized the field of radiation oncology, particularly in the management of medically inoperable patients with early stage non-small cell lung carcinomas, ${ }^{15}$ spine metastases, ${ }^{16}$ prostate cancer, ${ }^{17}$ and primary or metastatic liver cancers, ${ }^{18}$ with several prospective trials in these groups demonstrating excellent local control $(70 \%-80 \%$ and higher), with minimal acute and late toxicities $(<5 \%)$.

\section{SBRT planning and delivery}

Technical requirements for successful SBRT delivery include a modern linear accelerator with IGRT capabilities; and sophisticated radiation planning software with ability to perform multi-modal image registration (with contrast enhanced $\mathrm{CT}, \mathrm{MRI}, \mathrm{PET}$ ) and high precision radiotherapy dose distributions. Delivery methods must compensate for kidney motion, using one or more of: abdominal compression, respiratory gating (i.e., treating the tumour at a pre-specified point in the respiratory cycle), active breath hold techniques, and tumour tracking using implanted fiducial markers. Four-dimensional CT scanning is highly recommended, and aids in assessing kidney motion due to breathing (Fig. 1). ${ }^{19}$

Several planning techniques for SBRT have been discussed in the literature, including static conformal RT and intensity-modulated RT (IMRT), ${ }^{20}$ volumetric modulated arc therapy (VMAT), and robotic radiosurgery. ${ }^{21}$ The goals of planning regardless of technique are similar: to create a highly conformal dose around the target, with rapid dose fall-off beyond (Fig. 2).

Doses are prescribed such that the maximum dose within the target may exceed $120 \%$ to $130 \%$ of the prescription dose. Care must be taken to avoid high-dose RT to critical organs, including stomach, small bowel, large bowel, duodenum, spinal cord/cauda equina, chest wall/ribs, liver, and contralateral kidney. Criteria that avoid "low dose spillage" can be used to minimize dose to critical organs (Table 2).

The choice of RT dose is largely based on the premise that RCC is more sensitive to higher doses per fraction. Ning and colleagues characterized the radiosensitivity of RCC cell lines A498 and Caki-1, and determined the alpha-beta ratio (a marker of radiosensitivity) was lower than in other tumour cell lines (2.6 and $6.92 \mathrm{~Gy}$ ). They also demonstrated 


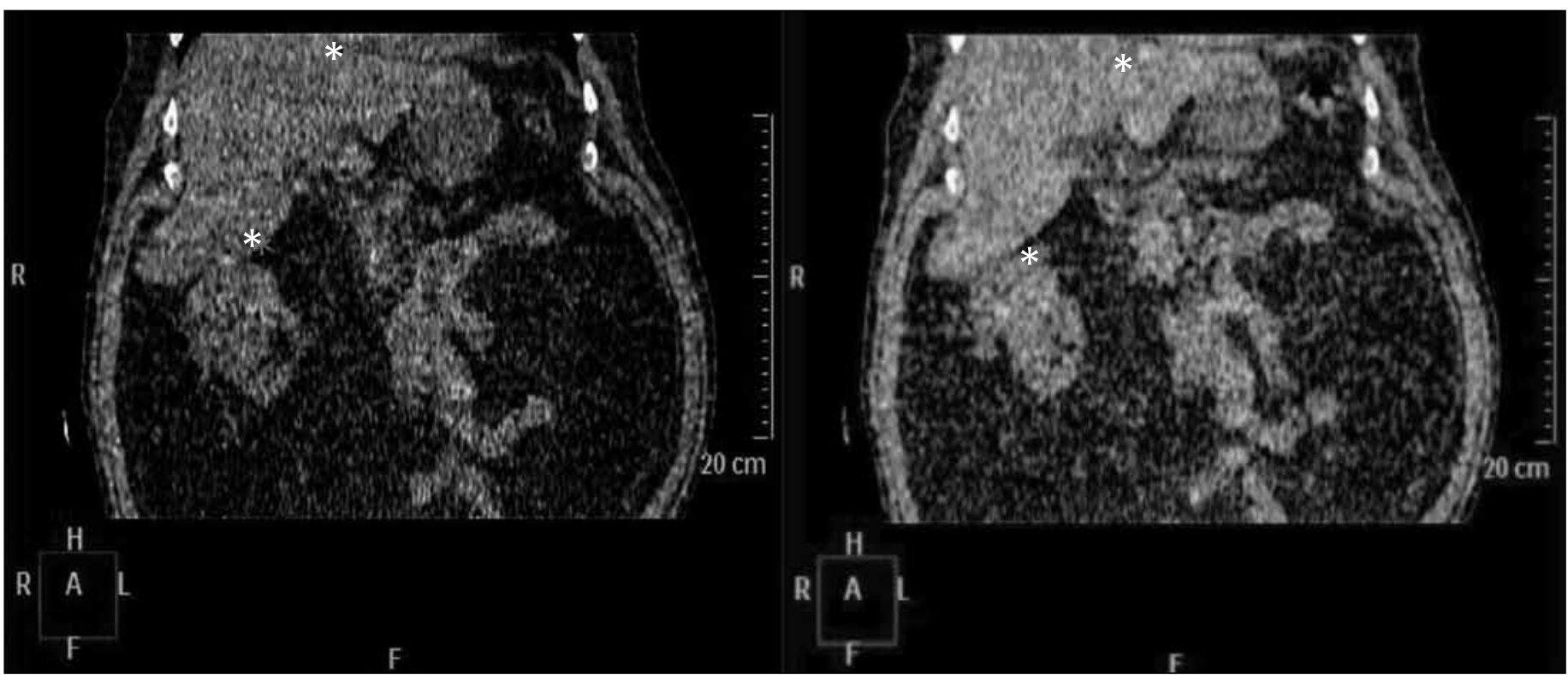

Fig. 1. 4-dimensional CT simulation of a right-sided RCC. Note the positional change (denoted by asterixes) of the superior aspect of the kidney, inferior liver edge and diaphragm through the respiratory cycle.

increased effective cell kill at higher doses per fraction. ${ }^{22}$ Based on this and other preclinical work, possible SBRT doses include 30 to 45 Gy in 3 to 5 fractions depending on critical organ tolerance and risk of toxicity (Table 2).

\section{Pre-clinical rationale for SBRT in RCC}

There has been a notion that RCC is a "radio-resistant" tumour, especially following CRT. Walsh and colleagues provided compelling work to suggest that high-dose, hypofractionated RT would result in RCC cell kill. ${ }^{23}$ They injected 19 nude mice into the R flank with A498 RCC cell lines, and irradiated 12 mice to 48 Gy in 3 fractions, while the other 7 mice were controls. At 7 weeks post-RT, there was progressive increase in the size of tumours in the control mice, and a $30 \%$ reduction in tumour volume in the irradiated mice. Histological tumour specimens of 4 sacrificed mice 4 weeks post-treatment showed no active mitoses, as compared to 9 to 14 mitoses/high powered field in 6 control mice.

\section{Clinical evidence of SBRT in RCC}

Unlike SBRT for other indications (lung, liver, spine), their role in treating primary RCC is relatively limited (Table 3). ${ }^{20,21,24-29}$ No randomized trials to date have evaluated SBRT in primary kidney cancer.

Siva and colleagues conducted a systematic review of 10 studies with 126 patients treated with SBRT for inoperable RCC, published in 2012.30 Three trials were prospective, and 7 retrospective, with the largest series being 33 patients, and there was no tumour size criteria or cutoff reported.
SBRT doses in these trials were variable, with most studies describing doses of 30 to $45 \mathrm{~Gy}$ in 3 to 5 fractions. One trial by Nomiya and colleagues reported a dose of 4.5 Gy $\times 16$ fractions, which may not necessarily fall within the true

\begin{tabular}{lc}
\hline Table 2. Five-fraction dose constraints for RCC SBRT \\
\hline Organ at risk & Maximum dose \\
\hline Treated kidney & Mean dose $<11.3 \mathrm{~Gy}$ \\
Both kidneys & V16.8 Gy $<67 \%$ \\
Spinal cord & V23 Gy $<0.35 \mathrm{cc}$ \\
& V14.5 Gy $<1.2 \mathrm{cc}$ \\
Stomach & Dmax $<32 \mathrm{~Gy}$ \\
& V18 Gy $<10 \mathrm{cc}$ \\
Duodenum & Dmax $<32 \mathrm{~Gy}$ \\
& V18 Gy $<5 \mathrm{cc}$ \\
Small bowel & V12.5 Gy $<10 \mathrm{cc}$ \\
& $\mathrm{Dmax}<35 \mathrm{~Gy}$ \\
Large bowel & V19.5 Gy $<5 \mathrm{cc}$ \\
& $\mathrm{Dmax}<38 \mathrm{~Gy}$ \\
Heart & V25 Gy $<20 \mathrm{cc}$ \\
& Dmax $<38 \mathrm{~Gy}$ \\
Chest wall/ribs & V32 Gy $<15 \mathrm{cc}$ \\
& $\mathrm{Dmax}<105 \%$ \\
Skin & V40 Gy $<10 \mathrm{cc}$ \\
Esophagus & Dmax $<39.5 \mathrm{~Gy}$ \\
Liver & V36.5 Gy $<10 \mathrm{cc}$ \\
& V27.5 Gy $<5 \mathrm{cc}$ \\
& V35 Gy $<0.035 \mathrm{cc}$ \\
& Mean dose $<18 \mathrm{~Gy}$ \\
& V21 Gy $<700 \mathrm{cc}$ \\
&
\end{tabular}

SBRT: stereotactic body radiotherapy; RCC: renal cell carcinoma; Gy: Gray; Dmax: maximum dose. $\mathrm{VXX}$ Gy $<X X \% / \mathrm{cc}$ - Volume of organ receiving at least $\mathrm{XX}$ Gy no more than $X X \% / c c$. 


\begin{tabular}{|c|c|c|c|c|c|c|c|}
\hline Study & $\begin{array}{l}\text { Study } \\
\text { type }\end{array}$ & $\begin{array}{c}\text { Patient } \\
\text { number }\end{array}$ & Tumour size & $\begin{array}{c}\text { Radiation dose } \\
\text { (Fractions) }\end{array}$ & Local control & Survival & Toxicity \\
\hline Wersall $^{24}$ & $\mathrm{R}$ & 8 & NR & $\begin{array}{l}26-32 \text { Gy (2) } \\
18-45 \text { Gy (3) } \\
28-48 \text { Gy (4) } \\
25-40 \text { Gy (5) }\end{array}$ & Crude local control 88\% & $5-y r$ OS $80 \%$ & $\begin{array}{c}50 \% \text { Grade I-II acute } \\
\text { No late toxicity observed }\end{array}$ \\
\hline Gilson ${ }^{25}$ & $\mathrm{R}$ & 33 & $2.4-1366 \mathrm{cc}$ & 40 Gy (5) & Crude local control $94 \%$ & NR & NR \\
\hline Svedman ${ }^{26}$ & $P$ & 5 & NR & $\begin{array}{l}20-30 \text { Gy (2) } \\
24-45 \text { Gy (3) } \\
28-48 \text { Gy (4) } \\
25-50 \text { Gy (5) }\end{array}$ & $\begin{array}{l}\text { Crude local control } \\
600-80 \%\end{array}$ & $\begin{array}{c}\text { Median } \\
\text { Survival } 32 \\
\text { months }\end{array}$ & NR \\
\hline $\mathrm{Teh}^{28}$ & $\mathrm{R}$ & 2 & NR & $24-40$ Gy (3-6) & No local failures observed & NR & NR \\
\hline Svedman ${ }^{27}$ & $\mathrm{R}$ & 7 & $2.3-6.8 \mathrm{~cm}$ & $\begin{array}{l}30 \text { Gy (3) } \\
40 \text { Gy (4) }\end{array}$ & Crude local control $86 \%$ & NR & $57 \%$ Grade I-II acute \\
\hline Nair $^{29}$ & $\mathrm{R}$ & 3 & $\begin{array}{l}\text { Mean size } \\
21.3 \mathrm{cc}\end{array}$ & 39 Gy (3) & $1-y r 100 \%$ & NR & No toxicity observed \\
\hline Pham $^{20}$ & $P$ & 20 & $\begin{array}{c}3-9 \mathrm{~cm} \\
22.7-322.5 \mathrm{cc}\end{array}$ & $\begin{array}{l}42 \mathrm{~Gy}(3) \\
26 \mathrm{~Gy}(1)\end{array}$ & NR & NR & $60 \%$ Grade $1-2$ acute \\
\hline Staehler ${ }^{21}$ & $\mathrm{P}$ & 40 & $7.5-120 \mathrm{cc}$ & 25 Gy (1) & 9-month $98 \%$ & & No late toxicity observed \\
\hline
\end{tabular}

definition of SBRT, and used carbon-ion RT, a technique that is not widely available. ${ }^{31}$ Overall, local control in all trials was between $86 \%$ and $100 \%$ at 2 years. Most trials had limited follow-up (median 2-3 years) and thus survival was rarely reported. Weighted rates of late toxicity in these trials were $3.8 \% .^{30,31}$

Since this systematic review was completed, 2 larger prospective cohort studies have been published. Pham and colleagues recently reported early toxicity results of a phase I trial using 42 Gy in 3 fractions (for $\geq 5$-cm tumors) or 26 Gy in 1 fraction (for $<5 \mathrm{~cm}$ ). ${ }^{20}$ Although no results are available for long-term control, toxicity was mild, with $60 \%$ of patients experiencing only grade 1 and 2 fatigue, nausea, and chest wall pain that was self-limiting. A second study of single fraction SBRT to a dose of 25 Gy in 40 patients (15 transitional cell carcinomas, 25 RCCs) was conducted by Staehler and colleagues. ${ }^{21}$ With a median follow-up of 28 months, crude local control was $87 \%$, and 5 -year overall survival was $80 \%$.

\section{Kidney toxicity following SBRT}

There is minimal evidence to date of SBRT-associated kidney injury or renal dysfunction. In a study by Svedman and

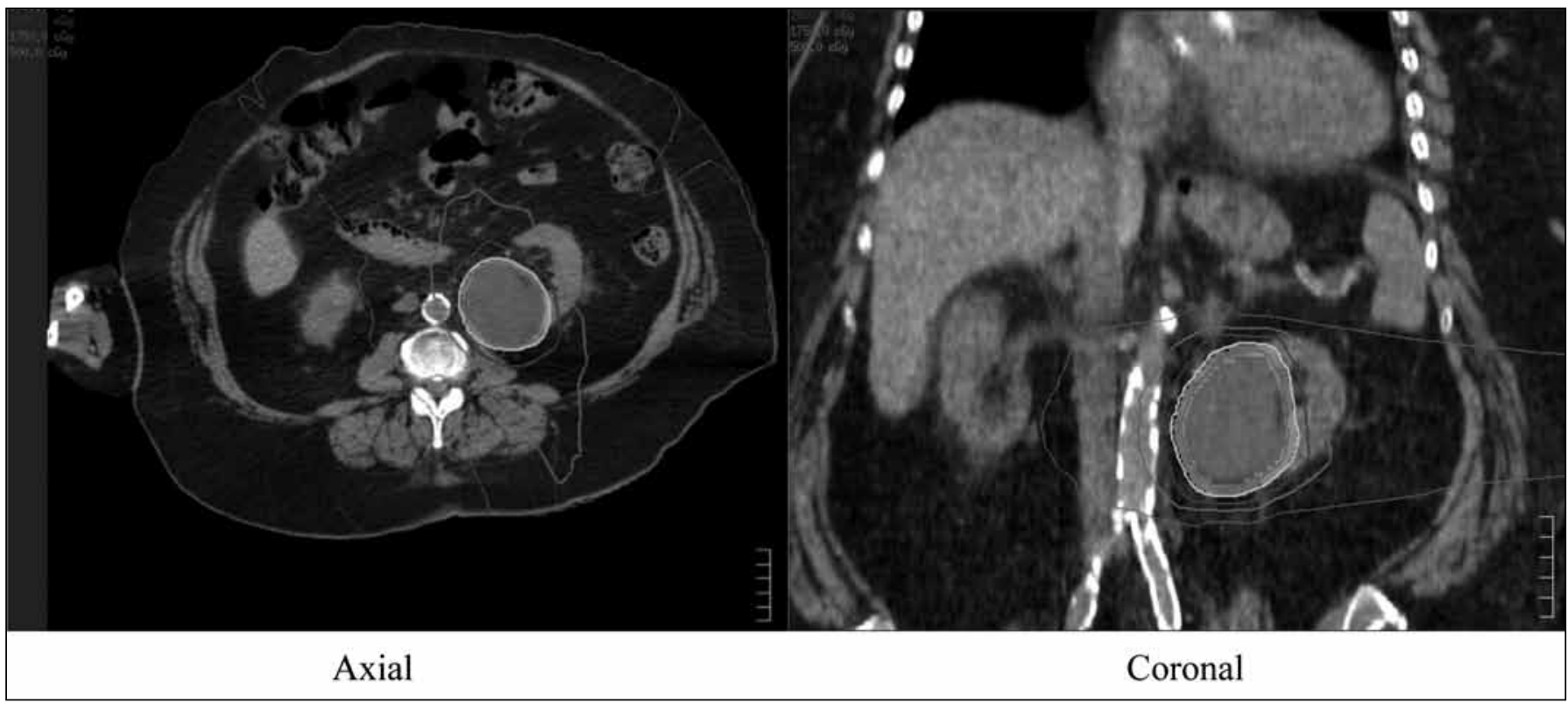

Fig. 2. SBRT dose distribution for a left RCC treated with a $35 \mathrm{~Gy}$ in 5 fraction VMAT plan. (Target volumes in grey colourwash). 
colleagues, 7 patients were treated with contralateral kidney metastases post-nephrectomy. ${ }^{27}$ In this series, no significant renal dysfunction was observed; all patients had normal serum creatinine levels prior to SBRT, and only 2 of 7 developed a rise in creatinine that stabilized long term. In the series by Staehler and colleagues, the median creatinine clearance did not significantly change from pre-SBRT (76.8 $\mathrm{mL} / \mathrm{min})$ to post-SBRT levels $(70.3 \mathrm{~mL} / \mathrm{min} ; p=0.89) .{ }^{21}$ In adults, there is no consensus on SBRT dose tolerance to the kidneys. The QUANTEC (Quantitative Analyses of Normal Tissue Effects in the Clinic) RT consortium confirmed this lack of consensus on safe doses to partial kidney volumes, and recommended that trials employing partial kidney RT/SBRT should be meticulous in their collection of baseline functional renal status, have close monitoring/ follow-up, and correlate toxicities with dose/volume data generated during radiation planning. ${ }^{32}$ Further defining the kidney by outlining the renal cortex and hila will yield even more robust long-term data.

\section{Future directions}

It is clear that the rationale to consider SBRT in inoperable RCC is compelling, and that the "radio-resistant" label to RCC in the SBRT era should be removed. The non-invasiveness, convenience, and good therapeutic ratio of SBRT make it an attractive option for medically frail patients. However, it is also clear that outcomes data are limited, and there should be an emphasis in pursuing large-scale, collaborative prospective trials of SBRT in this patient population to mirror the success story of early stage lung cancer. These trials should be aimed at collecting robust clinical, dosimetric, outcomes, and toxicity information at scheduled followup intervals to demonstrate the long-term safety of SBRT. Follow-up should include methods to adequately evaluate kidney function either via serial laboratory/biomarker analysis, quantitative imaging modalities, and/or regular cytological evaluation. Given the paucity of data on quality of life post-SBRT in general, it will be important to capture the impact of SBRT on quality of life and its cost-effectiveness compared to other modalities.

As a result, a prospective, multicentre Canadian collaborative effort led by investigators in Toronto-Sunnybrook and Hamilton is soon to begin, which will address many of the issues above, and will also carefully evaluate quality of life, health utilities, and cost-effectiveness in this patient population.

Interest in SBRT beyond the primary RCC setting is also intriguing in the setting of oligometastatic or oligoprogressive disease, in the pre-surgical and neoadjuvant setting, as well as in combination with targeted and novel agents. Such indications are beyond the scope of this review, but will hopefully continue to help further expand the role of SBRT in the management of RCC in general.

\section{Conclusion}

SBRT is an emerging application in the management of RCC, with pre-clinical and clinical evidence demonstrating promising early results with respect to durable local control and minimal toxicity. Large scale, collaborative prospective trials are further required to support its budding role, and this will hopefully lead to randomized trials in the future that will establish its relevance in comparison to, and in addition to, currently accepted therapies.

Competing interests: The authors all dedare no competing financial or personal interests.

This paper has been peer-reviewed.

\section{References}

1. Canadian Cancer Statistics 2014. Toronto, ON: Canadian Cancer Society 2014.

2. Rendon RA, Kapoor A, Breau R, et al. Surgical management of renal cell carcinoma: Canadian Kidney Cancer Forum Consensus. Can Urol Assoc J 2014;8:E398-412. http://dx.doi.org/10.5489/cuaj.1894

3. Pierorazio PM, Johnson MH, Ball MW, et al. Five-year Analysis of a Multi-institutional Prospective Clinical Trial of Delayed Intervention and Surveillance for Small Renal Masses: The DISSRM Registry. Eur Urol 2015. http://dx.doi.org/10.1016/i.eururo.2015.02.001

4. Schiavina R, Borghesi $M$, Dababneh $H$, et al. Small renal masses managed with active surveillance: Predictors of tumor growth rate after long-term follow-up. Clin Genitourin Cancer 2014.

5. Mason RJ, Abdolell M, Trottier G, et al. Growth kinetics of renal masses: Analysis of a prospective cohort of patients undergoing active surveillance. Eur Urol 2011;59:863-7. http://dx.doi.org/10.1016/i. eururo.2011.02.023

6. El Dib R, Touma NJ, Kapoor A. Cryoablation vs radiofrequency ablation for the treatment of renal cell carcinoma: A meta-analysis of case series studies. BJU Int 2012;110:510-6. http://dx.doi.org/10.1111/ j.1464-410X.2011.10885.x

7. Tunio MA, Hashmi A, Rafi M. Need for a new trial to evaluate postoperative radiotherapy in renal cell carcinoma: A meta-analysis of randomized controlled trials. Ann Oncol 2010;21:1839-45. http://dx.doi. org/10.1093/annonc/mdq028

8. Lee J, Hodgson $D$, Chow $E$, et al. A phase II trial of palliative radiotherapy for metastatic renal cell carcinoma. Cancer 2005;104:1894-1900. http://dx.doi.org/10.1002/cncr.21410

9. Hunter GK, Balagamwala EH, Koyfman SA, et al. The efficacy of external beam radiotherapy and stereotactic body radiotherapy for painful spinal metastases from renal cell carcinoma. Pract Radiat Oncol 2012;2:e95-e100. http://dx.doi.org/10.1016/i.prro.2012.01.005

10. Sahgal A, Roberge D, Schellenberg D, et al. The Canadian Association of Radiation Oncology scope of practice guidelines for lung, liver and spine stereotactic body radiotherapy. Clin Oncol (R Coll Radiol) 2012;24:629-39. http://dx.doi.org/10.1016/i.clon.2012.04.006

11. Leksell L. The stereotaxic method and radiosurgery of the brain. Acta Chir Scand 1951;102:316-9

12. Leksell L. Stereotactic radiosurgery. J Neurol Neurosurg Psychiatry 1983;46:797-803. http://dx.doi. org/10.1136/innp.46.9.797

13. Potters L, Kavanagh B, Galvin JM, et al. American Society for Therapeutic Radiology and Oncology (ASTRO) and American College of Radiology (ACR) practice guideline for the performance of stereotactic body radiation therapy. Int J Radiat Oncol Biol Phys 2010;76:326-32. http://dx.doi.org/10.1016/i. iirobp.2009.09.042

14. De Meerleer G, Khoo V, Escudier B, et al. Radiotherapy for renal-cell carcinoma. Lancet Oncol 2014;15:e170-7. http://dx.doi.org/10.1016/S1470-2045(13)70569-2

15. Timmerman R, Paulus R, Galvin J, et al. Stereotactic body radiation therapy for inoperable early stage lung cancer. JAMA 2010;303:1070-6. http://dx.doi.org/10.1001/jama.2010.261

16. Sahgal A, Bilsky M, Chang EL, et al. Stereotactic body radiotherapy for spinal metastases: Current status, with a focus on its application in the postoperative patient. J Neurosurg Spine 2011;14:151-66. http:// dx.doi.org/10.3171/2010.9.SPINE091005

17. Tan TJ, Siva S, Foroudi F, et al. Stereotactic body radiotherapy for primary prostate cancer: A systematic review. J Med Imaging Radiat Oncol 2014;58:601-11. http://dx.doi.org/10.1111/1754-9485.12213 
Swaminath and Chu

18. Hoyer $M$, Swaminath A, Bydder S, et al. Radiotherapy for liver metastases: A review of evidence. Int J Radiat Oncol Biol Phys 2012;82:1047-57. http://dx.doi.org/10.1016/i.ijrobp.2011.07.020

19. Swaminath A, Dawson LA. Image-guided radiotherapy strategies in upper gastrointestinal malignancies. Front Radiat Ther Oncol 2011;43:315-30. http://dx.doi.org/10.1159/000322470

20. Pham D, Thompson A, Kron T, et al. Stereotactic ablative body radiation therapy for primary kidney cancer: A 3-dimensional conformal technique associated with low rates of early toxicity. Int I Radiat Oncol Biol Phys 2014;90:1061-8. http://dx.doi.org/10.1016/i.i.jobp.2014.07.043

21. Staehler $M$, Bader $M$, Schlenker $B$, et al. Single fraction radiosurgery for the treatment of renal tumors. J Urol 2015;193:771-5. http://dx.doi.org/10.1016/i.juro.2014.08.044. Epub 2014 Aug 14.

22. Ning $S$, Trisler K, Wessels BW, et al. Radiobiologic studies of radioimmunotherapy and external beam radiotherapy in vitro and in vivo in human renal cell carcinoma xenografts. Cancer 1997;80(12 Suppl):2519-28. http://dx.doi.org/10.1002/(SICI) 1097-0142(19971215)80:12+<2519::AIDCNCR26>3.0.CO;2-E

23. Walsh L, Stanfield JL, Cho LC, et al. Efficacy of ablative high-dose-per-fraction radiation for implanted human renal cell cancer in a nude mouse model. Eur Urol 2006;50:795-800. http://dx.doi.org/10.1016/i. eururo.2006.03.021

24. Wersall PJ, Blomgren H, Lax I, et al. Extracranial stereotactic radiotherapy for primary and metastatic renal cell carcinoma. Radiother Oncol 2005;77:88-95. http://dx.doi.org/10.1016/..radonc.2005.03.022

25. Gilson B, Lederman G, Qian G, et al. Hypo-fractionated Stereotactic Extra-Cranial Radiosurgery(HFSR) for Primary and Metastatic Renal Cell Carcinoma. Int J Radiat Oncol Biol Phys 2006;66:S349. http:// dx.doi.org/10.1016/i.i.irobp.2006.07.656

26. Svedman C, Sandstrom P, Pisa P, et al. A prospective Phase II trial of using extracranial stereotactic radiotherapy in primary and metastatic renal cell carcinoma. Acta Oncol 2006;45:870-5. http://dx.doi. org/10.1080/02841860600954875
27. Suedman C, Karlsson K, Rutkowska E, et al. Stereotactic body radiotherapy of primary and metastatic renal lesions for patients with only one functioning kidney. Acta Oncol 2008;47:1578-83. http://dx.doi. org/10.1080/02841860802123196

28. Teh B, Bloch C, Galli-Guevara $M$, et al. The treatment of primary and metastatic renal cell carcinoma (RCC) with image-guided stereotactic body radiation therapy (SBRT). Biomed Imaging Interv J 2007;3:e6. http://dx.doi.org/10.2349/biii.3.1.e6

29. Nair VJ, Szanto J, Vandervoort E, et al. CyberKnife for inoperable renal tumors: Canadian pioneering experience. Can J Urol 2013;20:6944-9.

30. Siva $S$, Pham $D$, Gill $S$, et al. A systematic review of stereotactic radiotherapy ablation for primary renal cell carcinoma. BJU Int 2012;110(11 Pt B):E737-43. http://dx.doi.org/10.1111/j.1464410X.2012.11550.x

31. Nomiya $\mathrm{T}$, Tsuji $\mathrm{H}$, Hirasawa $\mathrm{N}$, et al. Carbon ion radiation therapy for primary renal cell carcinoma: Initial clinical experience. Int J Radiat Oncol Biol Phys 2008;72:828-33. http://dx.doi.org/10.1016/i. ijrobp.2008.01.043

32. Dawson LA, Kavanagh BD, Paulino AC, et al. Radiation-associated kidney injury. Int J Radiat Oncol Biol Phys 2010;76:S108-15. http://dx.doi.org/10.1016/.i.irobp.2009.02.089

Correspondence: Dr. Anand Swaminath, Department of Oncology, McMaster University; Juravinski Cancer Centre, 699 Concession Street, Hamilton, Ontario, L8V 5C2; swaminath@hhsc.ca; Dr. William Chu, Department of Radiation Oncology, Odette Cancer Centre, Sunnybrook Health Sciences Centre, University of Toronto, 2075 Bayview Ave., Toronto, ON M4N 3M5; william.chu@sunnybrook.ca 